\title{
Editorial
}

\section{The Anterior Pituitary Gland - Co-Ordinating an Alphabet of Peptides}

The pituitary has been described as the Master Gland, even as we progress through the contemporary era of comprehensive proteomic arrays $[1,2]$. The label is a reflection of the range of the gland's influences. The variety of contributions that the anterior pituitary gland makes to so many of the clearly observable events as well as covert metabolic processes in the body (e.g. stress, reproduction, growth) is a result of many pathways within the multi-cell tissue. The anterior pituitary is covered by a fibrous capsule, and the parenchyma is composed substantially of epithelial secretory cells arranged in cords or follicles. A network of fenestrated capillaries provides a system that enables transport of secretions to other distant tissues. The gland was until recent times summarised as having five endocrine cell types [3], which were later called corticotrophs, gonadotrophs, lactotrophs, somatotrophs and thyrotrophs, and additionally some apparently non-endocrine cells were identified, including folliculo-stellate cells. This model of the pituitary was a useful staging post for the investigative process. Biology is well fertilised with temporary hypotheses that enable questions to be formulated and prevailing views examined. There is sometimes danger that a plausible guess becomes sanctified as dogma. One can wonder if for a short time such occurred with this tidy model of the adenophypohysis, and in the mid 20th century some evidence for paracrine interactions were ignored by some researchers.

Nevertheless these ideas aroused considerable excitement, and were supported by much more detailed evidence than the earlier suggestions, proposed by Galen in the second century AD, that the pituitary was a receptacle for mucus that had drained from the brain through the pituitary stalk and filtered to the nasopharynx. In fact the speculatively inaccurate interpretation led to the gland being named from the Latin word for mucus, 'pituita', and the adjective 'pituitous' meaning mucoid was derived.

The adenohypophysis is a network of cells, which must co-ordinate their secretions so that the pituitary is able to respond with appropriate activity in particular circumstances. Further, pituitary cells are themselves dependent for their own differentiation and growth on a large group of compounds which are derived from the pituitary, such as nitric oxide, endothelin, and insulin-like growth factor. The hormones traditionally associated with the anterior pituitary gland were characterised, and the regulation for their secretion was proposed, by Geoffrey Harris, as being dependent on the capillaries connecting it to the hypothalamus. Then the releasing factors were discovered. In 1977 Roger Guilleman and Andrew Schally were awarded the Nobel Prize for their discoveries concerning the peptide hormone production of the brain. Interactions between these hypothalamic factors and intrapituitary compounds is an important component in regulating pituitary endocrine function (e.g. the GnRH- activin-follistatin module reviewed here [4]).

It was suggested that one type of endocrine cell was associated with one hormone (except gonadotrophs that were characterised as having two). This apparently sturdy scaffold, that was resting on careful experimental observations, nevertheless began to shudder as new observations became accepted but did not fit easily with the scheme. Co-localisation of hormones was detected in some cells e.g. prolactin with growth hormone (indeed the somatolactotroph is the subject of one of the reviews in this issue [5]), growth hormone or prolactin with gonadotrophins, and TSH $\beta$ with adrenocorticotrophic hormone and with growth hormone. Further, when cell populations that had been rich or depleted in a particular cell type were recombined, the results demonstrated that different types of cells interact to elicit a secreted product; thus a cell type was noted to not act in isolation from other types [6]. The relationship of the releasing factors from the hypothalamus had enticing clinical implications but at the same time became less certain [7]. In addition it seems that the folliculo-stellate cells act as an important communication system transmitting messages to the diverse cells within the pituitary (reviewed here [8]).

Subsequently, compounds that are potentially involved in these inter-cell paracrine processes have been identified [9]. Compounds were not confined to those secreted from the endocrine cells, and the non-endocrine cells such as folliculo-stellate cells have also been identified as a source of regulating peptides. Substances, such as activin [10], bradykinin [11, 12], cytokines [13], ... metalloproteinases [14], neurotensin [15], oxytocin [16, 17], ... urocortin [18], VEGF [19], neuropeptide W [20] ... and many, many more were found in the gland. Many compounds, as is well-recognised now, are not found exclusively in one tissue. An example is leptin, which first gained attention as a nutrition-related peptide, but is reviewed in this issue as a part-regulator of the ovulatory cycle [21]. On the other hand some petpides are recently identified and may be functional particularly in the hypothalamo-pituitary axis. One group of them, RFamide peptides, and the observations around them is reviewed here [22]. It would be possible (while admitting to a certain imprecision for some of the letters) to find pituitary compounds to start with every letter of the alphabet. The concept of paracrinicity and the importance of the microenvironment eventually took hold with regard to the pituitary $[6,23]$. The role of the extracellular matrix (ECM) also became recognised (reviewed in this issue [24]). However direct evidence for paracrine action is yet to be obtained for some of the peptides that are potential mediators of inter-cell communication.

Aberrations of intra-pituitary (i.e paracrine) factors may be underlying features of pituitary pathologies, such as adenomas which can occur in the endocrine cell types. The metabolic errors can take the form of gain or loss of function. Modern clinical understanding of the role of the anterior pituitary was advanced by the success of hypophysectomies for acromegaly performed 
by Herman Schloffer in 1907 and Harvey Cushing in 1909. Increased knowledge has been acquired from diverse areas, and in this issue one review focuses on bony fishes [25].

Further, cell types have been observed to not be scattered randomly through the organ. There is a regionalisation that can be expected to affect specific functional responses. Gonadotrophs are especially in the anterior-ventral portion [26] near the borders of the intermediate and posterior lobes [27]. In mice, gonadotrophs aggregate in the cephalic ventromedial area [28]. Prolactin-containing cells are distributed throughout the gland [29,30], although two groups of cells were distinguished, one centrally located and one forming a narrow peripheral rim on the gland [31]. In mice, lactotrophs are generally distributed except in the cephalic ventromedial area [28] and in chickens are localized in the cephalic lobe [32]. Lactotrophs exist in close proximity to gonadotrophs in some regions of the gland of rats and also horses [33-35]. Somatotrophs in rats are evenly distributed sagitally and rostrocaudally, but unevenly dorsoventrally [36]; in mice, somatotrophs are generally distributed except in the cephalic ventromedial area [28]; in chickens GH-secreting cells are localized in the caudal lobe [32]. Corticotrophs have mainly an even distribution, frequently in juxtaposition to somatotrophs [26] and are less frequently observed in the antero-ventral region and the area immediately adjacent to the intermediate lobe. In mice, corticotrophs are most commonly located near the ventral surface and in the lateral wings [28]. The scarce thyrotrophs are at the periphery of the gland [26], and in mice almost solely in the ventral region [28]. In an area near the intermediate lobe, GH cells, ACTH cells and TSH cells were not found [26] and the anterior-ventral portion of the gland contains few or no somatotrophs, corticotrophs, prolactin cells and thyrotrophs [26]. The effects of such regionalisation and the potential for paracrine interactions between cell types will affect functioning behaviour. It is suggested, for example, that the cells located in regions of the left lobe release more prolactin than those in right lobe areas, and cells from different regions are differentially responsive to hypothalamic secretagogues [37-39]. In fact in this issue it is noted that the distribution of cytokines, CXCL12 and CXCR4, was not homogeneous throughout the tissue, being undetectable in much of the gland and seen in some occasional zones of high expression [40].

There is a range of compounds and regulatory activities within the pituitary gland [41-43] and this issue reviews several aspects. One of the compounds, IGF-1, is found in different cell types in bony fishes and the integration and coordination of its roles is considered [25]. Many compounds are found in a number of places in the body, and will have diverse roles appropriate to each location. One of these compounds is the fascinating leptin, and its part in linking energy and reproductive function, acting on the expression of more than one pituitary hormone, is discussed in this issue [21]. The importance of the hypothalamus and local pituitary production combining to regulate growth in normal and pathological situations is noted and considered [40]. The effects on several cellular behaviours by a peptide makes understanding the gland a complex task. Examples are activin and follistatin, which may alter endocrine control, pituitary development and tumour growth and are reviewed in this issue [4]. Another paper considers one of the most recently revealed group of potential regulating factors, the RFamide peptides, and discusses evidence for its activity on pituitary cells [22]. Sitting amongst the well-recognised endocrine cells are those cells that are being assigned an increasingly prominent role in pituitary function, the folliculo-stellate cells; these are reviewed in detail, including observations that they exhibit characteristics associated with stem cells [8]. The distance that understanding of the pituitary has moved since the model that was envisaged at the time the releasing factors were discovered is illustrated by the investigation of the mixed-hormone cell, the somatolactotroph, and the involvement of follistatin, a nontraditional protein regulated by one of the first releasing factors identified, TRH [5]. The microenvironment is now well established as an important concept for understanding cell behaviour, and the activities that the extracellular matrix has been identified to exhibit in pituitary cell behaviour is reviewed in another manuscript [24].

This issue of The Open Neuroendocrinology Journal illustrates that while once the pituitary was described by several hormones and simply-defined cell types, the understanding of it is now much more complex. No one currently is tempted to be dogmatic about the detail. In addition this issue notes pituitary characteristics of several species. Understanding the fascinating network that resides in it is the basis of defining events in the pituitary. The associated processes are required to provide the activating and suppressing signals for physiological functioning of this disparate array of cells. Progress has been made; we await further observations that will assist in mapping the linkages that enable the pituitary to exert its profound effects on a wide range of distant organs.

\section{REFERENCES}

[1] Amar AP, Weiss MH. Pituitary anatomy and physiology. NeurosurgClin N Am 2003; 14: 11-23, v.

[2] Beranova-Giorgianni S, Giorgianni F, Desiderio DM. Analysis of the proteome in the human pituitary. Proteomics 2002; 2: 534-42.

[3] Pantic VR. The specificity of pituitary cells and regulation of their activities. Int Rev Cytol 1975; 40: 153-95.

[4] Bilezikjian LM, Vale WW. The local control of the pituitary by activin signaling and modulation. Open Neuroendocr J 2010; This issue.

[5] Kanasaki H, Oride A, Miyazaki K. Paracrine control of gonadotrophs by somatolactotrophs through TRH-induced follistatin production. Open Neuroendocr J 2010; This issue.

[6] Denef C. Paracrinicity: the story of 30 years of cellular pituitary crosstalk. J Neuroendocrinol 2008; 20: 1-70.

[7] Frohman LA. Clinical neuropharmacology of hypothalamic releasing factors. N Engl J Med 1972; 286: 1391-7.

[8] Morris J, Christian H. Folliculo-stellate cells: paracrine communicators in the anterior pituitary Open Neuroendocr J 2010; This issue.

[9] Evans JJ. Modulation of gonadotropin levels by peptides acting at the anterior pituitary gland. Endocr Rev 1999; 20: 46-67.

[10] Roberts V, Meunier H, Vaughan J, Rivier J, Rivier C, Vale W, Sawchenko P. Production and regulation of inhibin subunits in pituitary gonadotropes. Endocrinology 1989; 124: 552-4.

[11] Kariya K, Yamauchi A, Lee E. Sex-related difference of kinin level in rat pituitary gland. Life Sci 1987; 40: 407-12.

[12] Brann DW, Greenbaum L, Mahesh VB, Gao X. Changes in kininogens and kallikrein in the plasma, brain, and uterus during pregnancy in the rat. Endocrinology 1995; 136: 46-51.

[13] Haedo MR, Gerez J, Fuertes M, et al. Regulation of pituitary function by cytokines. Horm Res 2009; 72: $266-74$. 
[14] Tomita T. Matrix metalloproteinases and tissue inhibitors of metalloproteinases in pituitary adenomas: possible markers of neuroendocrine cells. Endocr Pathol 1997; 8: 305-313.

[15] Goedert M, Lightman SL, Nagy JI, Marley PD, Emson PC. Neurotensin in the rat anterior pituitary gland. Nature 1982; 298: 163-165.

[16] Dave JR, Culp SG, Liu L, Tabakoff B, Hoffman PL. Regulation of vasopressin and oxytocin synthesis in anterior pituitary and peripheral tissues. Adv Alcohol Subst Abuse 1988; 7: 231-4.

[17] Morel G, Chabot J-G, Dubois PM. Ultrastructural evidence for oxytocin in the rat anterior pituitary gland. Acta Endocrinol 1988; 117: $307-314$.

[18] Iino K, Sasano H, Oki Y, et al. Urocortin expression in human pituitary gland and pituitary adenoma. J Clin Endocrinol Metab 1997; 82: 3842-50.

[19] Gospodarowicz D, Lau K. Pituitary follicular cells secrete both vascular endothelial growth factor and follistatin. Biochem Biophys Res Commun 1989; 165: 292-8

[20] Dun SL, Brailoiu GC, Yang J, Chang JK, Dun NJ. Neuropeptide W-immunoreactivity in the hypothalamus and pituitary of the rat. Neurosci Lett 2003; 349: 71-4.

[21] Akhter N, Childs GV, Crane C. Pituitary leptin- A paracrine regulator of gonadotropes: A review. Open Neuroendocr J 2010; This issue.

[22] Anderson GM. Pituitary actions of RFamide peptides: a critique of the evidence. Open Neuroendocr J 2010; This issue.

[23] Jones TH, Brown BL, Dobson PRM. Paracrine control of anterior pituitary hormone secretion. J Endocrinol 1990; 127: 5-13.

[24] Evans JJ, Chitcholtan K. Extracellular matrix proteins and their functions in the anterior pituitary gland. Open Neuroendocr J 2010; This issue.

[25] Eppler E. The insulin-like growth factor I (IGF-I) within the bony fish pituitary: new morphofunctional and phylogenetic aspects Open Neuroendocr J 2010; This issue.

[26] Nakane PK. Classifications of anterior pituitary cell types with immunoenzyme histochemistry. J Histochem Cytochem 1970; 18: 9-20.

[27] Townsend J, Sneddon CL, Tortonese DJ. Gonadotroph heterogeneity, density and distribution, and gonadotroph-lactotroph associations in the pars distalis of the male equine pituitary gland. J Neuroendocrinol 2004; 16: 432-40.

[28] Baker BL, Gross DS. Cytology and distribution of secretory cell types in the mouse hypophysis as demonstrated with immunocytochemistry. Am J Anat 1978; 153: 193-216.

[29] Mukherjee P, Salada T, Hymer WC. Function of prolactin cells in the individual rat pituitry gland is location dependent. Mol Cell Endocrinol 1991; 76: 35-44.

[30] Nogami H, Yoshimura F. Fine structural criteria of prolactin cells identified immunohistochemically in the male rat. Anat Rec 1982; 202: 261-74.

[31] Papka RE, Yu SM, Nikitovitch-Winer MB. Use of immunoperoxidase and immunogold methods in studying prolactin secretion and application of immunogold labelling for pituitary hormones and neuropeptides. Am J Anat 1986; 175: 289-306.

[32] Lopez ME, Hargis BM, Dean CE, Porter TE. Uneven regional distributions of prolactin- and growth hormone-secreting cells and sexually dimorphic proportions of prolactin secretors in the adenohypophysis of adult chickens. Gen Comp Endocr 1995; 100: 246-54.

[33] Sato S. Postnatal development, sexual difference and sexual cyclic variation of prolactin cells in rats: special reference to the topographic affinity to gonadotroph. Endocrinol Jpn 1980; 27: 573-83.

[34] Horvath E, Kovacs K, Ezrin C. Junctional contact between lactotrophs and gonadotrophs in the rat pituitary. IRCS Med Sci 1977; 5: 511.

[35] Koves K, Kantor O, Scammell JG, Arimura A. PACAP colocalizes with luteinizing and follicle-stimulating hormone immunoreactivities in the anterior lobe of the pituitary gland. Peptides 1998; 19: 1069-1072.

[36] Perez FM, Hymer WC. A new tissue-slicing method for the study of function and position of somatotrophs contained within the male rat pituitary gland. Endocrinology 1990; 127: 1877-1886.

[37] Nagy GM, Boockfor FR, Frawley LS. The suckling stimulus increases the responsiveness of mammotropes located exclusively within the central region of the adenohypophysis. Endocrinology 1991; 128: 761-764.

[38] Porter TE, Frawley LS. Neurointermediate lobe peptides recruit prolactin-secreting cells exclusively within the central region of the adenohypophysis. Endocrinology 1992; 131: 2649-52.

[39] Vila-Porcile E, Barret A. Structural and functional differences between prolactin cells from the inner and outer zones of the male rat anterior pituitary. Cell Tissue Res 1996; 284: 247-59.

[40] Barbieri F, Bajetto A, Pattarozzi A, et al. The chemokine SDF1/CXCL12: a novel autocrine/paracrine factor involved in pituitary adenoma development. Open Neuroendocr J 2010; This issue.

[41] Evans JJ, Robinson G, Catt KJ. The luteinizing hormone response to oxytocin is steroid-dependent. Neuroendocrinology 1992; 55: 538-543.

[42] Szabo M, Kilen SM, Saberi S, Ringstrom SJ, Schwartz NB. Antiprogestins suppress basal and activin-stimulated follicle-stimulating hormone secretion in an estrogen-dependent manner. Endocrinology 1998; 139: 2223-8.

[43] Kineman RD, Kamegai J, Frohman LA. Growth hormone (GH)-releasing hormone (GHRH) and the GH secretagogue (GHS), L692,585, differentially modulate rat pituitary GHS receptor and GHRH receptor messenger ribonucleic acid levels. Endocrinology 1999; 140: 3581-6.

John J. Evans

(Guest Editor)

Centre for Neuroendocrinology and MacDiarmid Institute Department of Obstetrics and Gynaecology University of Otago

Christchurch, PO Box 4345

Christchurch 8140

New Zealand

Tel: 64 - $3-3641698$

E-mail: john.evans@otago.ac.nz

(C) John J. Evans; Licensee Bentham Open.

This is an open access article licensed under the terms of the Creative Commons Attribution Non-Commercial License (http://creativecommons.org/licenses/by-nc/3.0/) which permits unrestricted, non-commercial use, distribution and reproduction in any medium, provided the work is properly cited. 